\title{
Placental antibody transfer: influence of maternal HIV infection and placental malaria
}

\author{
M Isabel de Moraes-Pinto, Francine Verhoeff, Lyson Chimsuku, Paul J M Milligan, \\ Lalanga Wesumperuma, Robin L Broadhead, Bernard J Brabin, Peter M Johnson, \\ C Anthony Hart
}

Department of

Medical Microbiology,

University of

Liverpool, PO Box 147,

Liverpool L69 3GA

$M$ Isabel de

Moraes-Pinto

L Wesumperuma

C Anthony Hart

Department of

Immunology

$M$ Isabel de

Moraes-Pinto

P M Johnson

Department of

Paediatrics, Federal

University of Sao

Paulo, Sao Paulo,

Brazil

M Isabel de

Moraes-Pinto

Liverpool School of Tropical Medicine,

Liverpool

F Verhoeff

L Chimsuku

P J M Milligan

B J Brabin

Department of Paediatrics, Queen Elizabeth Central

Hospital, Blantyre,

Malawi

R L Broadhead

Correspondence to: Professor C A Hart

Email: cahmm@liv.ac.uk

Accepted 23 April 1998

\begin{abstract}
Aim-To determine the influence of placental malaria, maternal HIV infection, and maternal hypergammaglobulinaemia on transplacental IgG antibody transfer. Methods-One hundred and eighty materno-neonatal pairs from a Malawian population were assessed. Cord and maternal serum samples were tested for total serum IgG antibody titres using nephelometry, and for specific IgG antibody titres to Streptococcus pneumoniae, measles, and tetanus toxoid antibodies using an enzyme linked immunsorbent assay (ELISA).

Results-Multiple regression analyses showed that placental malaria was associated with a decrease in placental IgG antibody transfer to $S$ pneumoniae and measles to $82 \%$ and $81 \%$, respectively. Maternal HIV infection was associated with a reduction in IgG antibody transfer to $S$ pneumoniae to $79 \%$; raised maternal total serum IgG titres were correlated with $S$ pneumoniae and measles IgG antibody transfer reduction to $86 \%$ and $87 \%$, respectively. No effect was seen with tetanus toxoid antibody transfer.

Conclusion-The combined influence of placental malaria, maternal HIV infection, and maternal hypergammaglobulinaemia seems to be linked to the low transplacental antibody transfer observed in the Malawian population.

(Arch Dis Child Fetal Neonatal Ed 1998;79:F202-F205)
\end{abstract}

Keywords: malaria; HIV; antibody transfer; $S$ pneumoniae

The neonate can be regarded as an immune compromised host especially when premature. In addition to a series of defects in the non-specific immune system, the neonate's production of immunoglobulins is impaired. At birth a term neonate produces around $5 \%$ of adult levels of IgG; $20 \%$ of adult IgM and IgA production begins at birth. Nevertheless, neonatal blood contains large amounts of IgG. This is derived transplacentally from the maternal circulation. This process involves binding of IgG by Fc receptors to the surface of syncytitrophoblasts, active transport across the cell, and release into the fetal bloodstream. ${ }^{1}$ This process provides passive humoral immunity to neonates during their first months of life. The amounts of pathogen specific IgG transferred not only determine the degree and length of protection, but may also affect the success of the infant's vaccination programme after birth. ${ }^{1-6}$

Several clinical conditions can interfere with the materno-fetal transport of specific IgG antibodies across the human placenta. These include prematurity, ${ }^{7}$ maternal hypergammaglobulinaemia, ${ }^{8}{ }^{9}$ maternal HIV infection $^{10}{ }^{11}$ and placental malaria. ${ }^{12}$ In certain regions of Africa many of the above conditions coexist and the prevalence of infectious diseases preventable by vaccine is high among infant populations. ${ }^{13}$ It is not clear whether impaired transplacental antibody transfer could affect the efficacy of such vaccination regimens.

In this study we analysed the influence of placental malaria, maternal hypergammaglobulinaemia, maternal HIV infection, parity and prematurity on the efficiency of transplacental transfer of specific IgG antibodies to $S$ pneumoniae capsule, measles, and tetanus toxoid in mother-infant pairs from a Malawian population living in a malaria endemic area.

\section{Methods}

This study was carried out in the Shire Valley, Malawi, between March 1993 and September 1994. This is an endemic area for Plasmodium falciparum malaria, with a high prevalence of HIV infection in adult women. ${ }^{14}$ The 180 mother-newborn pairs analysed were collected as part of a longitudinal study of anaemia in pregnant women and their infants. The pairs were selected based on availability of sufficient sera for the several laboratory tests.

This work was approved by the Health Sciences Research Committee, Medical College, Malawi. Before enrolment, all women gave informed consent. A questionnaire was completed at recruitment and at delivery. These included information on malaria prophylaxis and treatment, maternal illness during pregnancy, gestational age and birthweight.

Cord blood was collected immediately after delivery from a large vein on the fetal side of the placenta. Maternal venous blood was collected during the first 24 hours of the puerperium from a peripheral vein. Serum samples were stored in aliquots at $-20^{\circ} \mathrm{C}$ until analysis in Liverpool.

Maternal HIV infection was defined by the presence of serum HIV antibodies determined by two different enzyme linked immunosorbent assay (ELISA) tests, as recommended by the World Health Organisatin when HIV infection prevalence in the population is above 
Table 1 Distribution of maternal HIV infection and placental malaria according to the babies' gestational age and birthweight

\begin{tabular}{llll}
\hline Neonates' classification & HIV seropositive & $\begin{array}{l}\text { Malaria positive } \\
\text { placenta }\end{array}$ & $\begin{array}{l}\text { HIV seropositive with } \\
\text { placental malaria }\end{array}$ \\
\hline Term adequate birthweight $(\mathrm{n}=149)$ & $28(18.8 \%)$ & $31(20.8 \%)$ & $6(4.0 \%)$ \\
Term low birthweight $(<10$ th centile) $(\mathrm{n}=6)$ & $2(33.3 \%)$ & $5(83.3 \%)$ & $2(33.3 \%)$ \\
Preterm $(\mathrm{n}=25)$ & $7(28.8 \%)$ & $10(40.0 \%)$ & $4(16.0 \%)$ \\
\hline
\end{tabular}

Percentages are of total numbers in each subgroup.

$10 \% .{ }^{15}$ These were the ICE HIV-1.0.2 (Murex; Dartford, UK) and the VIDAS HIV $1 / 2$ new (bioMérieux; Lyon, France).

Placental malaria infection was defined by the presence of parasites on thick or thin Giemsa stained films, prepared using blood collected from a deep incision performed on the maternal side of the placenta. A minimum of 200 fields were always examined and Plasmodium parasite species identified.

Total serum IgG concentrations were assayed by laser nephelometry using a Beckman Array Protein System (Beckman; Brea, USA). $S$ pneumoniae, measles, and tetanus toxoid specific serum IgG antibody titres were tested using "in-house" indirect ELISAs, developed as described before, ${ }^{11}$ but using the adsorbed tetanus toxoid vaccine BP (Evans Medical; Leatherhead, UK) as the tetanus antigen and the Edmonston measles vaccine strain to prepare the measles antigen.

Multiple regression was used to assess the effect of a number of variables on placental antibody transfer. For each specific antigen, the logarithm of neonatal specific serum IgG antibody titre was regressed on several predictors: the logarithm of maternal specific serum IgG titre, the logarithm of total maternal serum IgG titre, maternal HIV status (coded as 0 if negative and as 1 if positive), placental malaria infection (coded as 0 if negative and as 1 if positive), prematurity ( $<37$ weeks gestation) and parity (coded as 0 for primipara and 1 for multipara). Variables were removed from the model if non-significant. For 14 mother- neonate pairs, IgG measles antibodies were not detectable in either mother or neonate or both; the data for these pairs were omitted from some of the $\log$ regressions. $t$ tests on logtransformed data $(\ln \mathrm{X})$ were used to compare mean titres of maternal and neonatal IgG antibodies between groups; to avoid taking the log of zero, a small value corresponding to half of the detectable level of the ELISA assay was attributed to the samples with undetectable antibody titres.

\section{Results}

Among the 180 mother-newborn pairs analysed were 149 babies born at term with adequate birthweight (above the 10th centile), six born at term of low birthweight, and 25 preterm (less than 37 weeks of gestation). All neonates were singletons. Table 1 shows that there was a higher incidence of both maternal HIV infection and placental malaria infection in mother-newborn pairs where the baby was either term and of low birthweight, or preterm. Maternal HIV infection and placental malaria coexisted in only $4 \%$ of pairs of term normal birthweight babies, but in $33.3 \%$ of term babies with low birthweight, and in $16 \%$ of preterm neonates. All HIV infected mothers were asymptomatic (category A, according to the Centers for Disease Control classification).

Mean total serum IgG and measles antibody titres were significantly higher in HIV infected mothers compared with those not infected. Mean serum $S$ pneumoniae and tetanus toxoid IgG antibody titres were similar in HIV and

Table 2 Geometric means * of total serum IgG antibody to tetanus toxoid, measles and S pneumoniae in paired maternal and cord sera of HIV seropositive and seronegative motherst

\begin{tabular}{|c|c|c|c|c|c|c|}
\hline & \multicolumn{3}{|c|}{ Maternal serum $\operatorname{Ig} G$ antibody titre } & \multicolumn{3}{|c|}{ Cord serum IgG antibody titre } \\
\hline & $\begin{array}{l}\text { HIV seropositive } \\
\text { (range) }\end{array}$ & $\begin{array}{l}\text { HIV seronegative } \\
\text { (range) }\end{array}$ & $P$ value $\neq$ & $\begin{array}{l}\text { HIV seropositive } \\
\text { (range) }\end{array}$ & $\begin{array}{l}\text { HIV seronegative } \\
\text { (range) }\end{array}$ & Pvalue $\neq$ \\
\hline Total serum IgG (g/l) & $22.9(10.6-38.3)$ & $17.3(9.3-38.1)$ & $<0.001$ & $13.4(3.7-19.9)$ & $13.4(0.6-25.9)$ & 0.97 \\
\hline IgG anti $S$ pneumoniae (arbitrary units $/ \mathrm{ml}$ ) & $6.9(1.7-27.9)$ & $6.5(0.4-63.5)$ & 0.74 & $2.2(0.3-27.9)$ & $3.0(0.2-45.3)$ & 0.16 \\
\hline IgG anti measles (IU/ml) & $2.1(<0.16-46.9)$ & $1.1(<0.16-40.0)$ & 0.02 & $1.1(<0.16-37.7)$ & $1.7(<0.16-20.9)$ & 0.14 \\
\hline IgG anti Tetanus toxoid (IU/ml) & $0.8(0.1-4.3)$ & $0.7(0.03-6.5)$ & 0.47 & $0.7(0.07-3.3)$ & $0.6(0.02-4.5)$ & 0.78 \\
\hline \multicolumn{7}{|c|}{$\begin{array}{l}\star \text { Detransformed mean of } 1 \mathrm{n} X \text { values. } \\
\dagger \text { Only term babies with adequate birthweight were included. } \\
\ddagger \mathrm{t} \text { test. }\end{array}$} \\
\hline \multicolumn{7}{|c|}{$\begin{array}{l}\text { Table } 3 \text { Geometric means* of total serum IgG and specific IgG antibody to } S \text { pneumoniae, measles and tetanus toxoid in paired maternal and cord sera } \\
\text { with and without placental malariat }\end{array}$} \\
\hline & \multicolumn{3}{|c|}{ Maternal serum IgG antibody titre } & \multicolumn{3}{|c|}{ Cord serum IgG antibody titre } \\
\hline & $\begin{array}{l}\text { With placental } \\
\text { malaria (range) }\end{array}$ & $\begin{array}{l}\text { Without placental } \\
\text { malaria (range) }\end{array}$ & $P$ value $\neq$ & $\begin{array}{l}\text { With placental } \\
\text { malaria (range) }\end{array}$ & $\begin{array}{l}\text { Without placental } \\
\text { malaria (range) }\end{array}$ & $P$ value $\neq$ \\
\hline Total serum IgG (g/l) & $18.6(9.8-38.3)$ & $18.2(9.3-38.1)$ & 0.70 & $14.2(10.9-19.0)$ & $13.2(7.8-16.3)$ & 0.33 \\
\hline IgG anti $S$ pneumoniae (arbitrary units $/ \mathrm{ml}$ ) & $6.4(1.1-81.5)$ & $6.6(0.4-63.5)$ & 0.87 & $2.4(0.3-45.3)$ & $3.0(0.2-35.7)$ & 0.31 \\
\hline IgG anti measles $(\mathrm{IU} / \mathrm{ml})$ & $1.2(<0.16-20.0)$ & $1.2(<0.16-46.9)$ & 1.0 & $1.0(<0.16-13.9)$ & $1.3(<0.16-37.7)$ & 0.28 \\
\hline IgG anti tetanus toxoid (IU/ml) & $0.7(0.1-4.3)$ & $0.7(0.03-6.5)$ & 0.75 & $0.7(0.01-4.5)$ & $0.7(0.02-4.1)$ & 0.94 \\
\hline
\end{tabular}

* Detransformed mean of $1 \mathrm{n} \mathrm{X}$ values.

† Only term babies with adequate birthweight were included.

$\ddagger \mathrm{t}$ test. 
Table 4 Multiple regression estimates of the effects of placental malaria, maternal HIV infection and the level of total maternal serum IgG on placental IgG antibody transfer

\begin{tabular}{llll}
\hline $\begin{array}{l}\text { Serum IgG antibody } \\
\text { specificity }\end{array}$ & $\begin{array}{l}\text { Proportional reduction due } \\
\text { to placental malaria }\end{array}$ & $\begin{array}{l}\text { Proportional reduction } \\
\text { due to maternal HIV } \\
\text { infection }\end{array}$ & $\begin{array}{l}\text { Proportional reduction } \\
\text { due to raised maternal } \\
\text { IgG }\end{array}$ \\
\hline $\begin{array}{l}\text { S pneumoniae } \\
\text { Measles }\end{array}$ & $0.82(0.70,0.97)^{\star}$ & $0.79(0.65,0.95)^{\star}$ & $0.86(0.77,0.96)^{\star}$ \\
Tetanus toxoid & $0.81(0.68,0.97)^{\star}$ & $0.98(0.79,1.22)$ & $0.87(0.79,0.97)$ \\
\hline
\end{tabular}

The $95 \%$ confidence intervals are in parentheses.

* Indicates significant decrease $(\mathrm{p}<0.05)$.

non-HIV infected mothers (table 2). Mean maternal total serum IgG and antibody tires to $S$ pneumoniae, measles, and tetanus toxoid were not significantly different between mothercord pairs with or without placental malaria infection (table 3). These results refer to pairs with neonates born at term and with adequate birthweight, but similar figures were obtained when the whole sample was analysed (data not shown).

Placental transfer of specific IgG antibodies to $S$ pneumoniae was reduced by placental malaria, maternal hypergammaglobulinaemia, and maternal HIV infection to $82 \%, 79 \%$, and $86 \%$, respectively. Placental transfer of specific IgG antibodies to measles was reduced by placental malaria to $81 \%$ and maternal hypergammaglobulinaemia to $87 \%$. Maternal HIV seropositivity was not associated with reduced transfer of measles antibody. Placental transfer of specific IgG antibodies to tetanus toxoid was not reduced by any of the variables analysed.

Specific maternal IgG antibody titres were always positively associated with the corresponding cord antibody titres. Parity, prematurity, or previous malaria treatment did not influence the placental transfer of specific $S$ pneumoniae, measles, or tetanus toxoid IgG antibodies, and these variables were excluded from the regression analyses. Table 4 shows the proportional reduction in neonatal specific IgG antibody titres due to placental malaria infection, maternal HIV infection, and high maternal total serum IgG titres. The estimated reduction is the ratio of the expected cord titre when maternal serum IgG is $22.9 \mathrm{~g} / 1$ to the expected cord titre when maternal serum IgG is $14.9 \mathrm{~g} / \mathrm{l}$; these total serum IgG titres are the third and first quartiles, respectively, in mothers for this sample. Thus a 1.5 -fold increase in maternal total serum IgG titre is associated with a decrease in $S$ pneumoniae IgG antibody titre in the neonate to $86 \%$. Mean neonatal total serum IgG and serum IgG antibody titres to $S$ pneumoniae, measles, and tetanus toxoid were not significantly different $(p>0.05)$ between neonates born to HIV and non-HIVinfected mothers (table 2). Similarly, there were no significant differences between the mean neonatal total serum IgG and serum IgG antibody titres to $S$ pneumoniae, measles, and tetanus toxoid when mother-cord pairs with and without placental malaria infection were compared (table 3). Here again, the data refer to pairs with neonates born at term and with adequate birthweight; results were comparable when the whole sample was analysed (data not shown).

\section{Discussion}

Our aim was to assess the influence of HIV infection and placental malaria on placental IgG antibody transfer. $S$ pneumoniae, measles, and tetanus were the antibody specificities chosen because these infectious agents are important causes of morbidity and mortality in infants.

Although measles and tetanus immunisation has reduced the incidence of both diseases, there are still many children who die every year after acquiring natural infection in developing countries. ${ }^{13}$ Similarly, factors affecting $S$ pneumoniae antibody titres could affect vaccine efficacy to pneumococcal disease in infancy. In the absence of an effective pneumococcal vaccine for infants, maternal immunisation during pregnancy has also been evaluated as a strategy to improve passive antibody protection. ${ }^{16}$

Mean maternal total IgG titres were high in this Malawian population, and significantly increased in HIV infected mothers (tables 2 and 3). This could in part be due to repeated malaria infections and the coexistence of HIV infection. HIV seropositive mothers also had higher measles IgG antibody titres (tables 2 and 3). High measles and mumps antibody titres have been reported before in HIV infected patients. ${ }^{17}$ In a Brazilian population we have also shown that HIV infected mothers had significantly higher mean varicella zoster antibody titres than non-HIV infected mothers, but mean measles antibody titres were not significantly different between the two groups. ${ }^{11}$ Non-specific B cell activation could account for the high specific antibody titres in HIV infected individuals. ${ }^{17}$ Polyclonal activation is generally considered to be the explanation for the hypergammaglobulinaemia which occurs in subjects exposed to repeated malaria infections resulting from chronic mitogenic stimulation. ${ }^{18}$

Placental IgG antibody transfer was influenced independently by placental malaria infection, maternal HIV infection, and maternal total serum IgG titres. All three factors were associated with reduced placental transmission of pneumococcal IgG antibodies. Decreased transport of measles IgG antibodies was associated with placental malaria infection and maternal total IgG titres. Materno-fetal transmission of tetanus IgG antibodies was not affected by any of the variables tested, which was an unexpected result as a previous study has shown that high malaria parasite densities in the placenta are associated with decreased transplacental transfer of tetanus IgG antibodies using paired samples from Papua-New Guinea. ${ }^{12}$ Coastal Papua New Guinea has one of the highest vectorial capacities for $P$ falciparum malaria in the world and this might well explain the difference between the results from there and Malawi, as more frequent and higher density placental infections would be commonly expected to be more common in pregnant women in Papua New Guinea.

Maternal HIV infection and hypergammaglobulinaemia were associated with decreased placental IgG transfer for some antibody specificities, but not for others in our Brazilian study, with transfer of $S$ pneumoniae antibodies 
being the most greatly affected. ${ }^{11}$ In the same study measles IgG antibody transfer was reduced by both maternal HIV infection and high maternal total serum IgG. High maternal total $\mathrm{IgG}$ was also associated with a reduction in placental IgG antibody transfer in the Malawian population. Tetanus IgG antibody titres were reduced by maternal HIV infection in the Brazilian study. ${ }^{11}$ The finding that parity was not associated with reduced placental transfer was similar to observations from Papua New Guinea. ${ }^{12}$ The lack of association between prematurity and reduced placental antibody transfer in this study has been described by others ${ }^{19}{ }^{20}$ Interestingly, all studies where prematurity was not examined in relation to placental antibody transfer have been undertaken in populations with high titres of maternal total serum IgG. Although this finding might be a characteristic of materno-fetal transmission of antibodies in the presence of maternal hypergammaglobulinaemia, it could also indicate a bias introduced when analysing preterm neonates born at a wide range of gestational ages - from 30 to 37 weeks. This is the reason why, in the present study, maternal and neonatal total IgG and specific IgG antibody titres were analysed only for samples from term babies of normal birthweight.

Although there was a reduction in placental transfer of IgG antibodies to $S$ pneumoniae and measles, neonates from HIV infected mothers or from mothers with placental malaria infection did not have significantly lower measles and pneumococcal IgG antibody titres. This could relate to effects of maternal hypergammaglobulinaemia on antibody transfer. Michaux et $a l^{1}$ were the first to notice that the pattern of placental IgG transfer may change when maternal total serum IgG titres reach 15 $\mathrm{g} / \mathrm{l}$ : cord total IgG titres tend to be lower than the corresponding maternal values above that concentration. As all the Malawian sample had very high maternal total IgG titres, this factor might also be applicable in this population.

This study has shown that placental transfer to certain IgG antibody specificities is reduced and associated with maternal HIV infection, placental malaria, and maternal hypergammaglobulinaemia. It is not known why some antibody specificities are more affected and why interference with antibody transfer differs between populations. Also, it is not known how maternal HIV infection and placental malaria infection interfere with materno-fetal IgG antibody transmission, although malaria causes pathological damage in placental tissues. ${ }^{22}$ There is less evidence that HIV causes histological damage to the placenta. ${ }^{22}$

As factors influencing the efficiency of placental IgG antibody transfer are specific to particular populations, susceptibility to specific infections in infancy will vary correspondingly. Vaccine schedules might need to be modified to allow for these effects. However, overall IgG antibody transfer was good in this Malawian population, with adequate protective levels being achieved in most babies. It is difficult to identify that subgroup of infants who acquire the least maternal IgG antibody and who might benefit most from accelerated vaccination schedules. Screening tests would not be cost effective or possible in developing countries and, for this reason, an alternative emphasis might be placed on controlling maternal infection.

We gratefully acknowledge financial support from the European Union, Wellcome Trust, and the Brazilian Government (CNPq).

1 de Moraes-Pinto I, Hart CA. Transplacental antibody ransfer and neonatal immunity. $\mathrm{Br} \quad \mathcal{f}$ Hosp Med 1997;58:317-9

2 Reilly CM, Stokes J, Buynak EB, Goldner H, Hilleman MR. Living attenuated measles-virus vaccine in early infancy. Engl F Med 1961;265:165-9.

3 Sato H, Albrecht P, Reynolds DW, Stagno S, Ennis FA. Transfer of measles, mumps, and rubella antibodies from mother to infant - its effect on measles, mumps, and mother to infant - its immunisation. Am f Dis Child 1979;133:1240-3.

4 Claesson BA, Schneerson R, Robbins JB, et al. Protective levels of serum antibodies stimulated in infants by two injections of Haemophilus influenzae type b capsular polysaccharide-tetanus toxoid conjugate. $f$ Pediatr 1989;114:97-100.

5 Sarvas K, Kurikka S, Seppala IJT, Makela PH, Makela O. Maternal antibodies partly inhibit an active antibody response to routine tetanus toxoid immunisation in infants. F Infect Dis 1992;165:977-9.

6 Englund JA, Anderson EL, Steinhoff MC, et al. The effect of maternal antibody on the serological response and the incidence of adverse reactions following primary immunization with acellular and whole cell pertussis vaccines combined with diphtheria and tetanus toxoids. Pediatrics 1995;96:580-4.

7 Catty D, Drew R, Seger R. Transmission of IgG subclasses to the human foetus. In: Hemmings WA, ed. Protein transmission through living membranes. London: Elsevier/NorthHolland Biomedical Press, 1979: 64-70.

8 Gendrel D, Richard-Lenoble D, Blot P, Fribourg-Blanc A. Transfer des immunoglobulines et des anticorps antirougeoleux de la mère à l'enfant en Afrique et en Europe. Presse Med 1988; 17:1633-6.

9 Gendrel D, Richard-Lenoble D, Massamba MB, et al. Transfert placentaire des anticorps antitétaniques et protection du nouveau-né. Arch Fr Pediatr 1990;47:725-9.

10 de Moraes-Pinto MI, Farhat CK, Carbonare SB, et al. Maternally acquired immunity in newborns from women infected by the human immunodeficiency virus. Acta Paeinfected by the huma
diatr 1993;2: 1034-8.

11 de Moraes-Pinto MI, Almeida ACM, Kenj G, et al. Placental transfer and maternally acquired neonatal IgG immunity in HIV infection. F Infect Dis 1996;173:1077-84.

12 Brair M-E, Brabin BJ, Milligan P, Maxwell S, Hart CA. Reduced transfer of tetanus antibodies with placental malaria. Lancet 1994;343:208-9.

13 Ada G. Global aspects of vaccination. Arch Allergy Immunol 1995; 108:304-8.

14 Taha TE, Canner JK, Wangel A-M, et al. Research in human immunodeficiency virus in Malawi: the Johns Hopkins University-Ministry of Health Project. Malawi Med $\mathcal{F}$ 1994;10:6-11.

15 World Health Organisation. Global programme on AIDSRecommendations for the selection and use of HIV antibody tests. Wkly Epidemiol Rec 1992;20:145-9.

16 Shahid NS, Steinhoff MC, Hoque SS, Begum T, Thompson $\mathrm{C}$, Siber GR. Serum, breast milk, and infant antibody after maternal immunisation with pneumococcal vaccine. Lancet 1995 ; 346:1252-7.

17 Kövamees J, Sheshberadaran H, Chiodi T, et al. Accentuated antibody response to paramyxoviruses in individuals infected with human immunodeficiency virus. $7 \mathrm{Med}$ Virol 1988;26:41-8.

18 Greenwood BM, Whittle HC. Immunology of malaria in the tropics. London: Edward Arnold, 1981:1-306.

19 Boersma ER. Serum immunoglobulin IgG, IgM, and IgA in maternal cord blood pairs from infants of normal and low birthweights in Tanzania. Arch Dis Child 1981; 56:31-5.

20 O'Dempsey TJD, McArdle T, Ceesay SJ, et al. Meningococcal antibody titres in infants of women immunised with meningococcal polysaccharide vaccine during pregnancy. Arch Dis Child 1996;74: F43-6.

21 Michaux JC, Heremans JF, Hitzig WH. Immunoglobulin levels in cord-blood serum of negroes and caucasians. Trop Georg Med 1996;18:10-4.

22 Galbraith RM, Fox H, Hsi B, Galbraith GMP, Bray RS, Faulk WP. The human materno-foetal relationship in malaria II Histological, ultrastructural and immunopathological studies of the placenta. Trans $R$ Soc Trop Med Hyg 1980; 74: 61-72. 